\title{
CHROMATOSPECTROPHOTOMETRIC DETFRMINATION \\ OF RUTIN IN THE BUDS OF Sophora japonica
}

G. L. Genkina and T. T. Shakirov

UDC 547.972

At the present time, rutin is obtained from the buds of imported Sophora japonica. It has been shown previously [1] that the buds of S. japonica cultivated in Central Asia can also serve as an industrial source for the preparation of rutin. Here we give an account of a method of analyzing rutin that has been recommended for the pharmacopoeialarticle on the buds of domestic $\underline{\mathbf{S}}$ japonica.

To isolate the rutin, $2 \mathrm{~g}$ of the comminuted air-dry buds of $\mathrm{S}$. japonica that had been passed through a sieve with apertures of $0.5 \mathrm{~mm}$ was placed in a conical flask $(7 \overline{50}-1000 \mathrm{ml})$, and $5 \mathrm{~g}$ of quartz sand, 15 glass balls $(\mathrm{d}=5-10 \mathrm{~mm})$, and $150 \mathrm{ml}$ of methanol were added. The contents of the flask were shaken for $6 \mathrm{~h}$ and allowed to stand for $18 \mathrm{~h}$. A $0.2-\mathrm{ml}$ sample of the filtered methanolic extract was chromatographed by the descending method on type "C" ["medium"] paper in the $15 \%$ acetic acid system $\left(\mathrm{R}_{f}\right.$ of rutin 0.70 , $\mathbf{R}_{f}$ of quercetin 0.05 ) [2-5]. The rutin was detected on the chromatogram by its fluorescence in UV light (yellow-brown spot) and was eluted from the paper with $30 \mathrm{ml}$ of $60 \%$ methanol by shaking for $4 \mathrm{~h}$ (95-97\% desorption). The amount of rutin in the eluate was determined on an SF-4 spectrophotometer at $\lambda$ max $358 \mathrm{~nm}$.

Calculation was performed relative to a standard rutin which we prepared from a pharmacopoeia preparation by washing it three times with hot acetone and subsequently recrystallizing it from methanol in accordance with a known procedure [6].

It was established that the amount of rutin in the buds of $S$. japonica cultivated in Central Asia was 19.5-20.5\% (maximum deviation from the mean 0.54\%), while the flowers contained 16.5-16.0\%, the fruit before falling $3.0 \%$, the green shell of the fruit $3.5 \%$, and the heart of the fruit $0.3-0.4 \%$. The amount of rutin decreased at the end of the vegetation period, which agrees with literature information for $\underline{S}_{\text {. japonica }}$ [7].

\section{LITERATURE CITED}

1. E. F. Fedorovich, N. A. Vedeneev, and S. A. Zokhre, Med. Prom. SSSR, No, 10, 33 (1958).

2. V. A. Bandyukova, A Study of the Flavonoids of $\underline{S}$. japonica [in Russian], Author's Abstract, Leningrad (1962).

3. N. G. Yurova, Proceedings of the 1st All-Union Congress of Pharmacists [in Russian], Moscow (1970), p. 782.

4. V. I. Litvinenko et al., Rast. Res., 5, No. 3, 369 (1969).

5. G. A. Fedorova, Trudy Vsesoyuzn. N. -I. Vitaminn. In-ta, 6, 256 (1959).

6. G. L. Genkina, Ya. I. Eidler, T. T. Shakirov, and R. Sh. Yamatova, Khim. Prirodn. Soedin., 747 (1972).

7. J. F. Couch, J. Naghaski, and C. F. Krewsow, J. Amer. Chem. Soc., 74, 424 (1952).

Institute of the Chemistry of Plant Substances, Academy of Sciences of the Uzbek SSR. Translated from Khimiya Prirodnykh Soedinenii, No. 3, pp. 436-437, May-June, 1973. Original article submitted December 30, 1972.

(c) 1975 Plenum Publishing Corporation, 227 West 17th Street, New York, N.Y. 10011. No part of this publication may be reproduced, stored in a retrieval system, or transmitted, in any form or by any means, electronic, mechanical, photocopying, microfilming. recording or otherwise, without written permission of the publisher. A copy of this article is available from the publisher for $\$ 15.00$. 